\title{
INDIVISIBILIDADE SOCIOAMBIENTAL: POR UMA VISÃO INTEGRACIONISTA ENTRE OS DIREITOS SOCIAIS E A PROTEÇÃO AO MEIO AMBIENTE
}

\author{
INDIVISIBILITY SOCIOAMBIENTALIST: A INTEGRATIONIST VISION OF SOCIAL \\ RIGHTS AND AMBIENT PROTECTION
}

\author{
Ana Paula Cabral Balim \\ Graduada em Direito pelo Centro Universitário Franciscano - UNIFRA - Conclusão Agosto de 2010. \\ Pós-Graduada em Direito Ambiental pela Universidade Luterana do Brasil - ULBRA/RS - Conclusão Julho de 2012. \\ Advogada OAB/RS 82725.
}

\begin{abstract}
RESUMO
0 presente trabalho tem por objetivo estudar, através do método dialético, a relação existente entre os direitos humanos, sociais e a proteção ambiental com o intuito de estabelecer entre ambos uma relação de indivisibilidade essencial para que sejam eficazes, e para que componham o conceito socioambientalista, tendo em vista as grandes disparidades existentes entre a protecão ambiental e a proteção à sociedade humana. Analisa-se inicialmente a relação primitiva entre homem e natureza, e a sua posterior concretização no âmbito internacional através do movimento ambientalista e socioambiental. Em um segundo momento, trabalha-se a concepção de indivisibilidade advinda dos direitos humanos para, enfim, relacioná-la aos direitos sociais e à proteção ambiental, com intuito de justificar o conceito socioambientalista. Por fim, conclui-se que a questão socioambiental concretiza-se na indivisibilidade dos direitos humanos, sociais e ambientais, e para que haja efetividade de qualquer dos direitos em individualidade, deve-se considerar todos em conjunto, como indivisíveis.
\end{abstract}

Palavras-chave: direitos humanos; direitos sociais; indivisibilidade; proteção ambiental; socioambientalismo.

\begin{abstract}
The present work has for objective to study, through the dialectic method, the existing relation between the human rights, social and the ambient protection with intention to establish enters both an essential relation of indivisibility so that they are efficient, and so that they compose the socioambientalist concept, in view of the great existing disparities between the ambient protection and the protection to the human society being. One analyzes initially the primitive relation between man and nature, and their subsequent implementation in the international scope of the ambientalist movement until the socioambientalist. At as a moment, it works conception of indivisibility happened of the human rights for, at last, relating it the social rights and to the ambient protection, with intention to justify the socioambientalist concept. Finally, one concludes that the socioambient question is materializing in the indivisibility of the human, social and ambient rights, and so that it has effectiveness of any of the rights in individuality, it must be considered all in set, as indivisible.
\end{abstract}

Keywords: ambient protection; indivisibility; human rights; socioambientalist; social rights. 


\section{SUMÁRIO}

INTRODUÇAO; 1 INTRODUÇÃO AO SOCIOAMBIENTALISMO; 1.1 Homem X Natureza ou Homem prónatureza: A relação que desencadeou a crise ambiental mundial; 1.20 surgimento da proteção ambiental no âmbito internacional: do ambientalismo ao socioambientalismo; 2 A INDIVISIBILIDADE DOS DIREITOS HUMANOS APLICADA À QUESTÃO SOCIOAMBIENTAL; 2.1 Aplicação do princípio da indivisibilidade diante da questão socioambiental: proteção ao meio ambiente e a sociedade humana; CONCLUSÃO; REFERÊNCIAS.

\section{INTRODUÇÃO}

A preservação do meio ambiente, no seu sentido lato, bem como a necessidade de desenvolver medidas e projetos que regulem a utilização do mesmo, de maneira ecologicamente correta e sustentável, é tema de grande ênfase nos últimos anos.

O desenvolvimento das indústrias, da tecnologia e da sociedade, desencadeou o uso exacerbado dos meios naturais. Os interesses econômicos, políticos e empresariais se sobrepuseram diante da questão ambiental, de tal maneira, que a exploração daquilo que o meio ambiente oferece passou a ser usado como fonte inesgotável. A história de desenvolvimento do homem demonstra essa utilização de maneira inconsciente, pois não se tinha conhecimento nos séculos passados de que os recursos naturais seriam finitos, e como o progresso e o crescimento industrial eram o enfoque do momento, a utilização imoderada desses recursos acabava por se justificar.

Contudo, esta relação entre o homem e meio ambiente de características primitivas e insustentáveis se enraizou na cultura humana, de modo que por diversas gerações seguintes, ainda que timidamente, a natureza já começasse a demonstrar fragilidade e esgotabilidade, não parecia ser motivo suficiente para controlar o modo de produção capitalista que se instituiu.

0 homem não se percebia como parte do meio ambiente, apenas o utilizava como um meio de obter o que desejava, sem pensar nas consequências que esta utilização poderia acarretar.

Entretanto, se antigamente a natureza não respondia as destruições que o homem lhe causava, atualmente já não se pode dizer o mesmo. Por ser um bem de natureza finita e esgotável, a natureza que durante séculos foi explorada irrestritamente, foi acumulando problemas.

Os impactos ambientais de anos de degradação parecem ter explodido no início do século XX, e afetaram diretamente aquele que foi seu principal causador, o homem.

REDESG / Revista Direitos Emergentes na Sociedade Global - www.ufsm.br/redesg v. 1, n. 1, jan.jun/2012 
As mudanças climáticas drásticas, a confusão das estações, o degelo dos pólos, a incidência de tempestades cada vez maiores, enchentes, secas, falta de alimentos, de ambientes saudáveis, tudo, passou a atingir o ser humano, simplesmente pelo fato de que o homem é parte do meio ambiente e dele depende para existir.

Foi a partir de então, do início de tomada de consciência de que a degradação ambiental acabaria por atingir os direitos dos seres humanos a possuírem uma vida digna e saudável, princípio este fundamental à humanidade, que o meio ambiente passou da pauta de problemas secundários e paralelos a problema principal e urgente.

A interpretação do homem e natureza começou a ser considerada em conjunto, para que a proteção a ambas pudesse ser efetiva. Essa unicidade de interpretação da sociedade e meio ambiente, de que as mesmas são indivisíveis e interdependentes, advém da proteção aos direitos humanos, que de maneira brilhantemente sábia pode perceber que a proteção a pessoa humana dependerá da indivisibilidade desta com todas outras esferas do direito, inclusive a ambiental e social.

Essa concepção de interdependência deu consequência ao surgimento de outro conceito, e outra maneira de visualizar a proteção ambiental: o socioambientalismo.

É prudente destacar que o conceito de sociedade, discorrido durante toda a pesquisa, é fundamentado no entendimento de que sociedade é "o conjunto de pessoas que compartilham propósitos, gostos, preocupações e costumes, e que interagem entre si constituindo uma comunidade organizada". ${ }^{1}$ Bem como, o conceito de Meio Ambiente, sustenta-se na posição de Ávila Coimbra" ${ }^{2}$ onde "o conjunto dos elementos abióticos (físicos e químicos) e bióticos (flora e fauna), organizados em diferentes ecossistemas naturais e sociais" em que o homem encontra-se inserido individual e socialmente, "num processo de interação que atenda ao desenvolvimento das atividades humanas, à preservação dos recursos naturais e das características essenciais do entorno, dentro das leis da Natureza e de padrões de qualidade definidos".

Para a realização do presente estudo, utilizou-se do método de abordagem dialético ${ }^{3}$, pois a questão ambiental e social está em constante transformação, e ao mesmo tempo

\footnotetext{
${ }^{1}$ WIKIPÉDIA. A enciclopédia livre. Disponível em: <http://pt.wikipedia.org/wiki/Sociedade>. Acesso em: 24 nov. 2009.

2 COIMBRA, J.A.A. O outro lado do meio ambiente: uma incursão humanista na questão ambiental. Campinas, SP: Millennium, 2002, p. 32.

${ }^{3}$ Segundo SaintClair Araújo, o método dialético opõe-se a todo conhecimento rígido: tudo é visto em mudança constante, pois sempre há algo que surge e se desenvolve e algo que se desagrega e se transforma. Fonte: ARAÚJO, S.C.C. Métodos de pesquisa. Disponível em: <http://www.iesambi.org.br/apostila_2007/metodos_pesquisa.htm>. Acesso em: 20 jul.2012.
}

REDESG / Revista Direitos Emergentes na Sociedade Global - www.ufsm.br/redesg v. 1, n. 1, jan.jun/2012 
indivisível e interdependente de várias outras esferas como jurídicas, humanas, econômicas, políticas, históricas entre outras.

Quanto ao procedimento de pesquisa, pode-se dizer que foram aplicados dois métodos: o histórico e o comparativo, visto que a partir de acontecimentos, processos e instituições de modos de vida passados, introduziu-se uma influência direta sobre a sociedade e o meio ambiente atuais. Bem como, delinearam-se, durante o estudo, algumas comparações entre a sociedade e o meio ambiente do conceito antigo, com a concepção atual que se vivencia.

Por tudo isso, e por sua grande repercussão social, é que o presente tema vem exigindo uma atenção direcionada das autoridades públicas tanto em abrangência nacional quanto internacional. Afinal o planeta terra é um só e o meio ambiente também, ainda que cada região possua suas características específicas, a destruição de um implicará na do outro, e consequentemente afetará os seres que nele habitam. É neste ponto, que se verifica o problema chave da presente pesquisa, quando a falta de um meio ambiente sadio implica e interfere no direito à vida do ser humano, bem como no direito à saúde, moradia, qualidade de vida entre outros, não se está apenas diante de um problema ambiental, mas também de um problema social, e, portanto, tentar preservar o meio ambiente sem considerar a sociedade que o envolve, seria resolver um problema e dar ensejo ao surgimento de outros.

Com a presente pesquisa busca-se contribuir, para que uma nova tendência de valores morais e éticos seja introduzida diante dos direitos humanos sociais e de sua relação com a proteção ambiental. Objetiva-se com o mesmo, demonstrar que o direito supremo e fundamental a toda humanidade, que é o direito à vida em si e seu desenvolvimento com dignidade e saúde, sempre foi e sempre será indivisível da natureza, e que para que se efetive a tão importante preservação ambiental é indispensável que junto com a mesma, esteja a proteção aos direitos humanos e sociais.

\section{INTRODUÇÃO AO SOCIOAMBIENTALISMO}

\subsection{Homem X Natureza ou Homem pró-natureza: A relação que desencadeou a crise ambiental mundial}

A relação homem $x$ natureza sempre apresentou características complexas, o homem da antiguidade e até mesmo o moderno, sempre foram vistos como seres REDESG / Revista Direitos Emergentes na Sociedade Global - www.ufsm.br/redesg v. 1, n. 1, jan.jun/2012 
externos e superiores ao meio natural, criando-se um abismo entre as ciências da natureza e as ciências do homem.

0 antropocentrismo ${ }^{4}$, que coloca o ser humano no centro do universo, predominante durante a civilização industrial, por volta do século XIX, fundamentava a capacidade humana de dominar a natureza e tomá-la para si. Pensamento esse herdado do Ocidente, acabou por desencadear uma busca incessante de algo que comprovasse que o homem não era natureza, e que só efetivamente seria homem quando se tornasse um ser social.

Certo é afirmar que o homem é um ser social, e que da sociedade precisa para se desenvolver, contudo essa característica não o faz ser distinto dos outros seres vivos da natureza uma vez que estes também apresentam modo de vida em grupo e, portanto acabam sendo sociáveis.

O homem, entendido como uma espécie de animal, se distinguiria das demais pela sua capacidade de produzir cultura, característica essa que não o distancia da natureza, mas apenas destaca uma de suas qualidades.

Neste sentido, expõe o autor Carlos Walter Gonçalves:

O fato de as sociedades humanas desenvolverem ao longo do tempo um patrimônio de saber sem o qual cada indivíduo no interior de uma sociedadecultura não consegue viver, não quer dizer que os homens saltaram da natureza para a cultura. Na verdade desenvolvem sua natureza ${ }^{5}$.

Assim, a produção de cultura passa ser a sua especificidade natural. A capacidade desenvolvida pelo homem de ao longo de sua história criar normas, regras e instituições, é reflexo de sua própria natureza com estímulos que advém do meio ambiente em que habitam bem como das relações estabelecidas entre si.

Considerar o homem como parte indissociável da natureza não foi e ainda não é o pensamento predominante na sociedade. A ideia de progresso que predominou durante a industrialização, moldou o pensamento e a cultura das sociedades de tal maneira que

\footnotetext{
${ }^{4}$ SIRVINSKAS, L.P. Manual de direito ambiental. 7. ed. São Paulo: Saraiva, 2009, p. 13.

${ }^{5}$ GONÇALVES, C.W.P. Os (Des)caminhos do meio ambiente. São Paulo: Contexto, 2006, p. 92.

REDESG / Revista Direitos Emergentes na Sociedade Global - www.ufsm.br/redesg v. 1, n. 1, jan.jun/2012
} 
toda degradação ambiental se justificaria pelo progresso e produção para o desenvolvimento humano.

Além de decorrer da industrialização a depredação ambiental, decorre também do próprio desenvolvimento da sociedade, o crescimento populacional, o índice de desemprego e de pessoas de baixa renda, são fatores cruciais que influenciam diretamente no meio ambiente.

A questão ambiental está intimamente relacionada com o modo de como a sociedade se relaciona com a natureza. Nessas estão implicadas as relações sociais e as complexas relações entre o mundo físico-químico e o mundo orgânico. A dificuldade destas relações se encontra no fato de que o pensamento prevalente e herdado, afirma que a sociedade e a natureza são termos que se excluem. Contudo o que não se teve a capacidade de observar é que a sociedade estaria destruindo as fontes vitais à sua própria existência.

O ecologista Jean Dorst afirma em sua obra que:

[...] podemos afirmar, de acordo com todos os biólogos que o homem cometeu um erro capital pensando poder isolar-se da natureza e não respeitar certas leis de alcance geral. Existe, já há muito, um divórcio entre o homem e seu meio. 0 velho pacto que unia o primitivo e seu habitat foi rompido de forma unilateral pelo homem, logo que este considerou que já era suficientemente forte para seguir apenas as leis elaboradas por ele mesmo ${ }^{6}$.

Por predominar como característica no modo de vida humano a utilização desenfreada do meio ambiente, bem como a dissociação do homem ao meio natural, constituiu-se com o passar dos anos o que, atualmente, pode-se denominar de crise ambiental.

O problema, até então localizado, assumiu outras dimensões, e a partir deste século os impactos ambientais que o homem causou sobre o meio ambiente durante toda sua história começaram a desencadear em grandes catástrofes ambientais, na extinção de espécies e ecossistemas e assim por diante.

${ }^{6}$ DORST, J. Antes que a natureza morra: por uma ecologia política. 6. ed. São Paulo: Edgar Blucher, 1973, p. 378.

REDESG / Revista Direitos Emergentes na Sociedade Global - www.ufsm.br/redesg v. 1, n. 1, jan.jun/2012 
Suely Chacon tece considerações sobre alguns aspectos principais para desencadear da crise atual:

[...] aumento incontrolável da população mundial; processos industriais que têm como base o uso de energias não renováveis, que dependem do uso de matériasprimas também não renováveis e que usam tal quantidade de água, que a recarga natural não é suficiente; o aumento da produtividade agrícola que tem levado a novos desequilíbrios ecológicos; contaminação do mundo: desequilíbrios e disfunções de todo tipo que resultam do intercâmbio entre a natureza e a sociedade humana, como consequência involuntária do processo de industrialização; poluição psíquica; poluição térmica (efeito estufa). ${ }^{7}$

Da necessidade de transformar o modo de vida da sociedade atual, que trouxe consigo características egocêntricas e consumistas do modelo de sociedade padrão das décadas passadas, surge o conceito de desenvolvimento sustentável e sociável, ou seja, conforme expõe o Relatório de Brundtland, encomendado pelas Nações Unidas, a "humanidade tem a capacidade de atingir o desenvolvimento sustentável, ou seja, de atender às necessidades do presente sem comprometer a capacidade das futuras gerações de atender às próprias necessidades ${ }^{8}$."

Esta definição de desenvolvimento sustentável implica consequências diretas sobre o meio ambiente, uma vez que utilizá-lo sustentavelmente é garantir que as futuras gerações também usufruam dos mesmos recursos que são utilizados pela geração presente.

Desenvolver-se sustentavelmente, tanto no sentido empresarial quanto humano, seria ter consciência de que o homem e a natureza encontram-se em um mesmo patamar, sendo que ambos tem uma interligação para sua existência e quanto ao homem para sua própria subsistência. É um processo de mudança que deve ser instituído no sentido de que a exploração dos recursos, a orientação dos investimentos, o desenvolvimento tecnológico e a mudança institucional estejam de acordo com as necessidades atuais e futuras. Seria agir socialmente, pensando em preservar, não

\footnotetext{
7 CHACON, S.S. Reflexões sobre a crise ambiental: uma viagem até suas origens. Disponível em: <http://www.cofecon.org.br/index.php?option=com_content\&task=view\&id=796\&ltemid=51 >. Acesso em: 16 jul. 2012.

${ }^{8}$ COMISSÃO MUNDIAL SOBRE MEIO AMBIENTE E DESENVOLVIMENTO. Nosso futuro comum. Rio de Janeiro: Fundação Getúlio Vargas, 1988.
}

REDESG / Revista Direitos Emergentes na Sociedade Global - www.ufsm.br/redesg v. 1, n. 1, jan.jun/2012 
somente para o uso próprio e individualista do hoje, mas também pensando no direito das futuras gerações que necessitarão tanto quanto a geração presente dos recursos que o meio ambiente tem a oferecer, uma vez que é através deste que se dará prosseguimento a existência humana.

A Comissão Mundial sobre o Meio Ambiente e Desenvolvimento, instituída em 1988, já afirmava:

Tomamos um capital ambiental emprestado às gerações futuras, sem qualquer intenção ou perspectiva de devolvê-lo. Elas podem até nos maldizer por nossos atos perdulários, mas jamais poderão cobrar a dívida que temos para com elas. Agimos desta maneira porque podemos escapar impunes: as gerações futuras não votam, não possuem poder político ou financeiro, não tem como opor-se as nossas decisões ${ }^{9}$.

Por advir da sociedade a crise ambiental reflete diretamente na mesma, e depende dela para ser resolvida. Se o homem se diferencia das outras espécies por ser dotado de inteligência, razão e cultura, só se poderá esperar dele atitudes que possam mudar o contexto atual do meio ambiente.

É necessário reconciliar o homem com a natureza, para que o mesmo possa firmar um novo pacto que permitirá a sobrevivência do mundo selvagem e simultaneamente permitirá que o homem recupere o equilíbrio material e moral que atualmente está lhe faltando.

Neste entendimento, assim se expressa Jean Dorst:

\begin{abstract}
Assegurar-se-á, salvando a humanidade, a preservação de seres vivos que constituem o conjunto da biosfera, da qual essa humanidade depende inteiramente. Ou se consegue salvar o homem e a natureza, conjuntamente, numa feliz harmonia, ou a nossa espécie estará condenada a desaparecer com os últimos restos de um equilíbrio que não foi criado para dificultar o desenvolvimento da humanidade, mas sim para the servir de contexto ${ }^{10}$.
\end{abstract}

Para que exista uma real consciência ambiental e social há ainda, em pleno século XXI, um longo caminho, sendo necessária não só a valorização do meio ambiente, mas do próprio homem, para que este possa vir a despertar para sua real condição na natureza, não se colocando acima ou externo dessa.

\footnotetext{
${ }^{9}$ COMISSÃO MUNDIAL SOBRE MEIO AMBIENTE E DESENVOLVIMENTO. Op. cit..

${ }^{10}$ DORST, J. Op. cit.

REDESG / Revista Direitos Emergentes na Sociedade Global - www.ufsm.br/redesg v. 1, n. 1, jan.jun/2012
} 


\subsection{0 surgimento da proteção ambiental no âmbito internacional: do ambientalismo ao socioambientalismo}

A concepção histórica de proteção ambiental que se observa nos séculos anteriores ao XX é um desconhecimento ou falta de consciência por parte da sociedade, cientistas e governo em relação à questão ambiental.

$\mathrm{Na}$ época acreditava-se que a própria natureza se renovaria dos estragos causados pelo homem, e mesmo com o grande desenvolvimento das ciências de observação da natureza, como física e química, no período entre o século XVIII e XIX, as ameaças ao desequilíbrio natural não foram identificadas. A busca pelo progresso tratado como um ideal a ser atingido por todas as sociedades acabava por inibir qualquer atitude mais rígida em relação aos reflexos que tal progresso causaria sobre o meio ambiente.

Os efeitos do desenvolvimento industrial acabaram por fazer com que a questão ambiental fosse tratada como questão secundária, sendo pensada apenas por alguns intelectuais e políticos. A maior parte da população estava interessada apenas em desfrutar das promessas de consumo que a sociedade "fordista", caracterizada por um processo de produção e de consumo em massa, lhes proporcionava.

Este modelo juntamente com a falta de consciência da sociedade como um todo pelas questões ambientais, ensejaram uma intensificação dos efeitos das atividades de produção e consumo sobre o meio ambiente.

Do desenvolvimento da sociedade, devem ser ressaltados alguns acontecimentos cruciais ocorridos durante o transcurso da história, que acabaram por refletir no comportamento social dos seres humanos.

As duas grandes Revoluções, a Francesa e a Industrial, sustentaram o predomínio da ciência e tecnologia sobre todas as ações humanas, a razão torna-se soberana, e a partir dela se justificam todas as atividades do homem. Este momento da história é baseado na ideia do Iluminismo e Liberalismo Econômico, onde o domínio sobre a natureza justifica-se pela razão, característica do Iluminismo, seguida e fortificada pelo 
modo de produção capitalista, característica do Liberalismo, a partir deste contexto a sociedade definitivamente cedeu aos ditames da produção e consumo.

Assim sustenta Leff:

0 processo civilizatório da modernidade fundou-se em princípios de racionalidade econômica e instrumental que moldaram as diversas esferas do corpo social: os padrões tecnológicos, as práticas de produção, a organização burocrática e os aparelhos ideológicos do Estado. A problemática ecológica questiona os custos socioambientais derivados de uma racionalidade produtiva fundada no cálculo econômico, na eficácia dos sistemas de seus meios tecnológicos ${ }^{11}$.

Posteriormente no período entre as Grandes Guerras Mundiais, houveram grandes transformações na sociedade em todos seus aspectos, inclusive das primeiras manifestações ambientalistas.

Este período entre as duas Grandes Guerras Mundiais foi marcado por várias revoluções sociais e políticas, que acabaram por consolidar os pilares do capitalismo, sendo que os recursos utilizados para que estas guerras, principalmente a segunda, acontecessem acabaram por desenvolver os setores de telecomunicações, transportes, economia entre outros, aproximando e, consequentemente, diminuindo a extensão do mundo. As novas tecnologias descobertas pelo ser humano the proporcionavam uma sensação de poder, que por diversas vezes foi extrapolado, elas representavam a solução para os problemas cotidianos em termos de conforto, comodidade e qualidade de vida da sociedade, contudo também serviram como meio de destruição da natureza e do próprio homem.

Foi efetivamente na década de 1960, após o lançamento das bombas atômicas, que se presenciou o início do movimento de luta a favor do meio ambiente, conforme afirma Leonardo Boff:

O pavor suscitado pelo lançamento de bombas atômicas sobre Hiroshima e Nagasaki, em 1945, foi tão profundo que mudou o estado de consciência da humanidade. Introduziu-se a perspectiva de destruição em massa, acrescida posteriormente com a fabricação de armas químicas e biológicas, capazes de ameaçar a biosfera e o futuro da espécie humana. Antes, os seres humanos se permitiam fazer guerras convencionais, explorar os recursos naturais, desmatar,

\footnotetext{
${ }^{11}$ LEFF, E. Saber ambiental: sustentabilidade, racionalidade, complexidade, poder. Petrópolis, RJ: Vozes, 2001, p.133.

REDESG / Revista Direitos Emergentes na Sociedade Global - www.ufsm.br/redesg v. 1, n. 1, jan.jun/2012
} 
jogar lixo nos rios e gases na atmosfera, e não havia grandes modificações ambientais. A consciência tranquila assegurava que a Terra era inesgotável e invulnerável e que a vida continuaria a mesma e para sempre em direção ao futuro. Esse pressuposto não existe mais ${ }^{12}$.

Após este período, de 1970 até meados de 1974, ainda que caracterizado por um retrógado jeito de agir e pensar sustentavelmente aconteceram também vários encontros e conferências com o intuito de alertar o mundo para a proteção ao meio ambiente. Expressa o artigo sobre Complexo Ambiental e sua evolução:

Entre os fatos mais importantes deste período, citam-se: a realização do primeiro Dia da Terra, nos Estados Unidos em 22 de abril de 1970; a realização da Conferência da ONU para o Ambiente Humano em Estocolmo (Noruega), em 1972; O lançamento dos livros Limits to growth (Limites para o crescimento), editado pelo Clube de Roma que reunia as Nações capitalistas mais ricas, e The ecologist, a blueprint for survival ( 0 ecologista um projeto para sobrevivência) ambos em 1972; a primeira crise do petróleo em 1973, em que os membros da OPEP (Organização dos países exportadores de petróleo) reduziram a produção para elevar o preço do produto ${ }^{13}$.

Em 1972, a realização da Conferência de Meio Ambiente das Nações Unidas ${ }^{14}$, em Estocolmo, acabou sendo um marco para o ambientalismo internacional, evento constituído pela participação de 113 países teve como resultado a criação da “Declaração de Estocolmo” e a instauração do “Programa das Nações Unidas para o Meio Ambiente (PNUMA)".

Conforme afirma Rafael Santos de Oliveira,

[...] Muito embora não seja um documento obrigatório juridicamente, conduziu a mudanças políticas decorrentes de sua força moral. Com base na Declaração de Estocolmo consegue-se formalizar, num documento escrito, metas a serem seguidas pelos países para que se consiga alcançar um nível de desenvolvimento econômico e ambiental de forma a um não interferir negativamente no outro ${ }^{15}$.

\footnotetext{
${ }_{12}$ BOFF, L. Ética e moral: a busca dos fundamentos. Petrópolis, RJ: Vozes, 2003, p.32.

13 ADM, Aula. Complexo ambiental: conceitos e evolução histórica. Disponível em: <http://www.aulaadm.pro.br/GEST\%C3\%830_SOCIOAMBIENTAL.CAP\%C3\%8DTULO2.pdf>. Acesso em: 14 jul. 2009.

14 UNIVERSAL. Declaração de Estocolmo sobre Meio Ambiente Humano, de 16 de junho de 1972. Conferência das Nações Unidas. em:<http://www.dhnet.org.br/direitos/sip/onu/doc/estoc72.htm>. Acesso em: 13 out. 2009.

${ }_{15}$ OLIVEIRA, R.S. Direito ambiental internacional: o papel da soft law em sua efetivação. Ijuí, RS: Unijuí, 2007, p. 138.

REDESG / Revista Direitos Emergentes na Sociedade Global - www.ufsm.br/redesg v. 1, n. 1, jan.jun/2012
} 
A partir da realização da mesma surgiram diversas iniciativas ambientais, pelo mundo inteiro a consciência de que algo deveria ser feito para frear a degradação ambiental tomou força e o problema ambiental passou a ter característica e visão social.

As manifestações ambientais seguiram como uma "gangorra" entre altos e baixos, dependendo do período e acontecimentos da época em que se vivia, a preocupação tomava proporções maiores ou menores.

A consciência ambiental começava a se desenvolver diante da sociedade, mas de forma muito tímida. Foi a partir da segunda metade da década de 80 , que se evidenciou a formação de um segundo movimento, o chamado movimento socioambiental, que surge a partir de articulações políticas entre os movimentos ambientais e sociais, com a finalidade de redemocratização.

O direito socioambiental envolve não só o direito ambiental propriamente dito, mas também os direitos indígenas, a preservação do patrimônio cultural, histórico e étnico, além da função social da propriedade, direito à saúde, bem estar, ambiente ecologicamente equilibrado, enfim, direitos sociais, humanos, todos tutelados pela Constituição Federal.

Afirma o autor Carlos Frederico Marés de Souza que,

Os bens socioambientais são todos aqueles que adquirem essencialidade para a manutenção da vida de todas as espécies (biodiversidade) e de todas as culturas humanas: (sociodiversidade). Assim, os bens ambientais podem ser naturais ou culturais, ou se melhor podemos dizer, a razão da preservação há de ser predominantemente natural ou cultural se tem como finalidade a bio ou a sociodiversidade, ou a ambos, numa interação necessária entre o ser humano e o ambiente em que vive ${ }^{16}$.

A implementação de uma legislação ambiental mais vasta e a realização de conferências mundiais sobre o meio ambiente serviram de impulso à concretização do movimento socioambiental.

Em 1987, por exemplo, foi divulgado o Relatório das Nações Unidas “Nosso Futuro Comum", como o primeiro relatório que defendeu o conceito de desenvolvimento

\footnotetext{
${ }^{16}$ SOUZA FILHO, Carlos Frederico Marés de. Introdução ao direito socioambiental. In: LIMA, André (Org.) 0 direito para o Brasil socioambiental. Porto Alegre: Fabris, 2002, p. 38.

REDESG / Revista Direitos Emergentes na Sociedade Global - www.ufsm.br/redesg v. 1, n. 1, jan.jun/2012
} 
sustentável denunciando a rápida devastação ambiental e o risco que a escassez dos recursos naturais acarretaria ao planeta.

Foi a partir da publicação deste Relatório que se evidenciou a necessidade da convocação de uma nova Conferência das Nações Unidas sobre Meio Ambiente e Desenvolvimento, a chamada “Eco-92”, realizada no Brasil.

O tema central do encontro situava-se na instituição de meios de cooperação entre diversos países, propondo-se a lidar com os problemas ambientais globais, tais qual afirma Rafael Santos de Oliveira “[...] poluição, mudança climática, destruição da camada de ozônio, uso e gestão dos recursos marinhos e de água doce, desmatamento, desertificação e degradação do solo, resíduos perigosos e a perda da diversidade biológica ${ }^{17}$."

A Conferência introduziu de uma vez por todas o tema meio ambiente, na pauta de assuntos internacionais. No Brasil, especificamente, foi a partir da década de 1980 que se pode observar uma legislação mais voltada à tutela ambiental. Com a inserção de um capítulo específico na Constituição Federal de 1988, sobre os Direitos ambientais, da maneira como foi colocado, verificou-se a possibilidade de consagrar a tutela ambiental e relacioná-la com diversos outros ramos do direito. Na feição exposta pelos artigos 225 e seguintes da Carta Magna, o direito ao meio ambiente interage acentuadamente com o direito à vida e à saúde, todos estes direitos fundamentais com vistas à proteção da dignidade humana. Assim, com esta nova relação de direitos que se interligam, e dependem uns dos outros, voltados primordialmente a manutenção da vida individual e socialmente, vislumbrou-se o surgimento de um novo conceito de direitos, mais amplo e abrangente, chamado de direito socioambiental.

Neste diapasão leciona José Afonso da Silva:

O que é importante é que se tenha a consciência de que o direito à vida, como matriz de todos os demais direitos fundamentais do Homem, é que há de orientar todas as formas de atuação no campo da tutela do meio ambiente. Cumpre compreender que ele é um fator preponderante, que há de estar acima de quaisquer outras considerações como as de desenvolvimento, como as de respeito ao direito de propriedade, como as de iniciativa privada. Também estes são garantidos no texto constitucional, mas, a toda evidência, não podem primar

${ }^{17}$ OLIVEIRA, Rafael Santos de. Op. cit., p. 144.

REDESG / Revista Direitos Emergentes na Sociedade Global - www.ufsm.br/redesg v. 1, n. 1, jan.jun/2012 
sobre o direito fundamental à vida, que está em jogo quando se discute a tutela da qualidade do meio ambiente ${ }^{18}$.

O direito socioambiental é de natureza transindividual e difusa, característica esta que gera como consequência certa desmotivação por parte dos titulares destes direitos, de buscar juridicamente a sua tutela, considerando que há a inexistência de vantagem pessoal e direta nestes tipos de casos. No Brasil, existem alguns instrumentos processuais que visam a garantir o acesso a justiça ambiental, dentre os quais, a ação popular e a ação civil pública, ambas ações visam proteger direitos coletivos.

As políticas públicas que se desenvolvem com o intuito de proteger o meio ambiente, já não podem mais se distanciar de políticas que envolvam também a sociedade. Afirma, neste sentido, Juliana Santilli que:

[...] um novo paradigma de desenvolvimento deve promover não só a sustentabilidade estritamente ambiental - ou seja, a sustentabilidade de espécies, ecossistemas e processos ecológicos - como também a sustentabilidade social - ou seja, deve contribuir também para a redução da pobreza e das desigualdades sociais e promover valores como justiça social e equidade ${ }^{19}$.

Este movimento se consolidou baseado na ideia de que as políticas públicas ambientais, só teriam eficácia se incluíssem políticas de cunho social. Como a exploração dos recursos naturais é feita pelas comunidades, a possibilidade de preservação dos mesmos depende exclusivamente do modo de utilização e conscientização da própria sociedade.

o socioambientalismo passou a ser observado como uma saída ao preservacionismo tradicional, que se distanciava das lutas por justiça social e pela inclusão da sociedade na conservação da biodiversidade. Para muitos preservadores tradicionais a participação da população, principalmente a mais pobre, na conservação do meio ambiente significava uma ameaça.

Em todas estas convenções realizadas e instituídas, o tema meio ambiente veio enfatizado em conjunto com a questão social. Se em toda sua história e evolução o meio

\footnotetext{
${ }^{18}$ SILVA, José Afonso da. Direito Ambiental constitucional. São Paulo: Malheiros, 2002. p.70.

19 SANTILLI, J. Socioambientalismo e novos direitos: proteção jurídica a diversidade biológica e cultural. São Paulo: IIEB, 2005.

REDESG / Revista Direitos Emergentes na Sociedade Global - www.ufsm.br/redesg v. 1, n. 1, jan.jun/2012
} 
ambiente serviu apenas como um meio, um recurso, para a utilização do homem no que lhe bem aprouvesse, com o passar dos anos e o surgimento de reflexos ambientais sobre a sociedade este pensamento já não teria mais fundamento.

Neste sentido, Rafael Santos de Oliveira assevera que:

Percebe-se que a tutela do meio ambiente, por meio do surgimento de um novo direito, requer uma análise complexa e em sintonia com os atuais dilemas socioambientais a que se encontra submetida toda a humanidade. Com isso, passa a prevalecer um entendimento de que o Direito Ambiental do século 21 não deve ser confundido com a mera proteção dos bens naturais. [...] Trata-se, portanto, de um direito com caráter horizontal, pois abrange diferentes ramos ${ }^{20}$.

Ou seja, ainda que a sociedade tenha estabelecido de maneira errônea um valor meramente econômico e consumista sobre os recursos ambientais por ser característica do modelo de vida da época, deles nunca se distanciou. Foi a falta de percepção do que esta utilização desenfreada acarretaria para o futuro, que fez com que a sociedade que até então caracterizava a natureza e seus recursos como um simples meio, sentissem na pele, no ar, nas águas, a necessidade de identificá-la como um fim esgotável e indispensável para a sobrevivência de toda humanidade.

\section{A INDIVISIBILIDADE DOS DIREITOS HUMANOS APLICADA À QUESTÃO SOCIOAMBIENTAL}

\subsection{Aplicação do princípio da indivisibilidade diante da questão socioambiental: proteção ao meio ambiente e a sociedade humana}

Os direitos humanos, ou seja, os direitos do homem individual e do homem em coletividade vivendo em sociedade são concebidos tanto em âmbito nacional quanto internacional como os direitos primordiais de uma sociedade, são os direitos e liberdades básicos de todos os seres humanos.

\footnotetext{
${ }^{20}$ OLIVEIRA, Rafael Santos de. Op. cit., p. 114.

REDESG / Revista Direitos Emergentes na Sociedade Global - www.ufsm.br/redesg v. 1, n. 1, jan.jun/2012
} 
A historicidade dos direitos humanos representa conforme afirma Flávia Piovesan que, “estes não são um dado, mas um construído, uma invenção humana em constante processo de construção e reconstrução ${ }^{21 "}$, ou seja, é fruto de lutas e ação social da própria sociedade em busca da dignidade humana.

Foi efetivamente, após a Segunda Guerra Mundial que os direitos humanos se constituíram, entre 1945 e 1948 os Estados, tomando consciência das atrocidades que haviam ocorrido naquele período, buscaram reconstruir o ideal de proteção humana, em virtude dos reflexos que a sua ruptura durante a guerra havia causado sobre toda humanidade. Neste mesmo contexto, conforme afirma Flávia Piovesan:

\begin{abstract}
Nasce ainda a certeza de que a proteção dos direitos humanos não deve se reduzir ao âmbito reservado de um Estado, porque revela tema de legítimo interesse internacional. Sob esse prisma, a violação dos direitos humanos não pode ser concebida como questão doméstica do Estado, e sim como problema de relevância internacional, como legítima preocupação da comunidade internaciona ${ }^{22}$.
\end{abstract}

Passando a ter caráter universal a proteção internacional se dá, principalmente, a partir de quatro importantes documentos: a Carta das Nações Unidas (1945), a Declaração Universal dos Direitos Humanos (1948), o Pacto Internacional dos Direitos Civis e Políticos (1966) e o Pacto Internacional dos Direitos Econômicos, Sociais e Culturais (1966).

A Declaração Universal dos Direitos Humanos ${ }^{23}$ foi redigida em 1948, pela Assembleia Geral das Nações Unidas, e trouxe em sua gama de características o caráter de amplitude, onde se apresenta um conjunto de direitos e faculdades pelos quais um ser humano não pode desenvolver sua personalidade sem, também conferir aos direitos humanos o caráter de universalidade, ou seja, aplicável a todas as pessoas do mundo.

\footnotetext{
${ }^{21}$ PIOVESAN, F. Direitos humanos e o direito constitucional internacional. 10. ed. São Paulo: Saraiva, 2009, p. 111.

22 PIOVESAN, Flávia. Op. cit., p. 121.

${ }^{23}$ UNIVERSAL. Declaração Universal dos Direitos Humanos, de 10 de dezembro de 1948. Assembleia Geral das Nações Unidas, Resolução 217(A) III. Disponível em: <http://www.mj.gov.br/sedh/ct/legis_intern/ddh_bib_inter_universal.htm>. Acesso em: 12 out. 2011.

REDESG / Revista Direitos Emergentes na Sociedade Global - www.ufsm.br/redesg v. 1, n. 1, jan.jun/2012
} 
Nesse sentido se reconhece o indivíduo como um ser pertencente a uma sociedade humana, sendo sujeito de direito.

A importância da Declaração Universal dos Direitos Humanos é muito abrangente. Ela compreende uma ampla variedade de direitos humanos, tais como direito à vida, direito à integridade, liberdade de expressão e informação e direitos políticos.

Há de se observar que anteriormente a promulgação da Declaração Universal dos Direitos Humanos, havia um consentimento doutrinário no sentido de estabelecer categorias de gerações (dimensões) aos direitos humanos. Segundo Bobbio ${ }^{24}$, a subdivisão se dava em primeira geração, compreendida nos direitos civis e políticos, segunda geração, do qual fazem parte os direitos econômicos e sociais e por fim terceira geração, onde se apresentam os direitos coletivos.

Os direitos de primeira geração confirmam-se em direitos civis e direitos políticos que embasaram a concepção liberal clássica, eles baseiam-se em uma clara demarcação entre Estado e não Estado, fundamentada no contratualismo de fundamento individualista. Com a aquisição das liberdades civis, surgiu a reivindicação pela participação na vida política através da extensão do direito de voto às classes menos favorecidas. Nessa geração o titular de direitos é o indivíduo, que se opõe ao Estado. Os principais direitos garantidos foram o direito à vida, à propriedade, à igualdade, à liberdade de expressão, à imprensa entre outros.

A segunda geração advém da primeira em um contexto onde, apesar de já reconhecidos os direitos civis e políticos, a desigualdade social e a exploração a classe proletária, desencadearam uma promoção as ideias socialistas que reivindicava a intervenção estatal, no qual o Estado passa a ter papel de devedor de direitos sociais e econômicos à sociedade. Busca-se do Estado a prestação de assistência social, à saúde, educação, trabalho, entre outras.

Por fim, a terceira geração e que no âmbito da pesquisa atual é a que mais interessa, caracteriza-se por uma tomada de consciência da sociedade em relação a determinar padrões de qualidade de vida dos povos e a solidariedade para com os ${ }^{24}$ BOBBIO, N. A era dos direitos. Rio de Janeiro: Campus, 1997, p.3.

REDESG / Revista Direitos Emergentes na Sociedade Global - www.ufsm.br/redesg v. 1, n. 1, jan.jun/2012 
mesmos. Esse conjunto de direitos, chamados de direitos coletivos, tem sua maior referência no âmbito internacional, pois visam a abranger não somente um país ou determinados Estados, mas sim toda humanidade em sua universalidade e indivisibilidade. A evolução da sociedade e a globalização acabam por exigir a efetivação desses direitos. Antônio Augusto Cançado Trindade, afirma em uma de suas obras que:

\begin{abstract}
Estes novos direitos não restringem, mas sim ampliam, aprimoram e fortalecem o corpus dos direitos humanos já reconhecidos: revelam novas dimensões de implementação dos direitos humanos e contribuem a clarificar o contexto social em que todos se inserem. Além disso, levantam um desafio: o da necessidade de expandir e enriquecer até mesmo o nosso próprio universo jurídico-conceitual, de repensar todo o direito em face da complexidade das novas e múltiplas relações jurídicas que se apresentam, para fazer face às novas exigências de proteção do ser humano na esfera global e para estabelecer as bases de um futuro direito comum da humanidade, com as correspondentes obrigações erga omnes ${ }^{25}$.
\end{abstract}

Paulo Bonavides assinala em relação a esta terceira dimensão que:

Com efeito, um novo pólo jurídico de alforria do homem se acrescenta historicamente aos da liberdade e da igualdade. Dotados de altíssimo teor de humanismo e universalidade, [...] tendem a cristalizar-se neste fim de século enquanto direitos que não se destinam especificamente à proteção dos interesses de um indivíduo, de um grupo ou de determinado Estado. Tem primeiro por primeiro destinatário o gênero humano mesmo, num momento expressivo de sua afirmação como valor supremo em termos de existencialidade concreta. [...] Emergiram eles da reflexão sobre temas referentes ao desenvolvimento, à paz, ao meio-ambiente, à comunicação e ao patrimônio comum da humanidade. ${ }^{26}$

Os direitos de terceira geração se enfatizam pela sua titularidade coletiva, se dirigindo a questões que afetam não só uma pessoa, na sua individualidade, mas sim a uma sociedade, comunidade. Caracterizam estes direitos, por exemplo, o direito ao meio ambiente saudável, à autodeterminação dos povos entre outros.

José Luiz Bolzan de Morais afirma que, quando se adentra na terceira geração de direitos, tem-se a percepção que se está diante de uma nova realidade para os direitos

\footnotetext{
${ }_{25}^{25}$ TRINDADE, A.A.C. A proteção internacional dos direitos humanos. São Paulo: Saraiva, 1992, p. 58.

${ }^{26}$ BONAVIDES, P. Curso de direito constitucional. 7. ed. São Paulo: Malheiros, 1998, p.523.

REDESG / Revista Direitos Emergentes na Sociedade Global - www.ufsm.br/redesg v. 1, n. 1, jan.jun/2012
} 
fundamentais, onde suas pretensões atingirão inevitavelmente a comunidade como um todo. $^{27}$

Assim, a inovação da Declaração foi trazer as três gerações em conjunto em um único documento consagrando o direito a indivisibilidade dos direitos humanos.

Com a Declaração se objetiva colocar em igualdade de importância os direitos civis e políticos e os direitos econômicos, sociais e culturais, bem como afirmar a indivisibilidade e interdependência de tais direitos. Quando a Declaração conjuga o valor de liberdade com o de igualdade, se funda a nova concepção dos direitos humanos onde as três gerações ao invés de se distanciarem, passam a interagir e estabelecer relações de dependência.

Flávia Piovesan, em sua primada obra, afirma que, "apresentando os direitos humanos uma unidade indivisível, revela-se esvaziado o direito a liberdade quando não assegurado o direito à igualdade; por sua vez, esvaziado, revela-se o direito à igualdade quando não assegurada a liberdade ${ }^{28 "}$.

Nesse sentido, os direitos humanos passam a constituir um complexo único e indivisível no qual todos outros ramos de direito vão estar interdependentes entre si. Sustentar a indivisibilidade dos direitos humanos é afirmar que o mesmo não se completa se não estiver relacionado com outras áreas do direito que acabam por interferir diretamente nos seus ditames. Ou seja, os direitos humanos para terem efetividade, precisam estabelecer dependência com os direitos civis, políticos, sociais, econômicos, ambientais e assim por diante.

O caráter de indivisibilidade encontra fundamento na afirmação de que os direitos humanos precisam da presença de todas as gerações em conjunto, para que possam se concretizar. Ainda, que a indivisibilidade e interdependência se concretizem quando há a relação entre vários ramos do direito, contemporaneamente há dois ramos específicos que vem exigindo cada vez mais esta interpretação: o direito à proteção ambiental e o direito social.

\footnotetext{
27 MORAIS, J.L.B. Do direito social aos interesses transindividuais: o estado e o direito na ordem contemporânea. Porto Alegre: Livraria do Advogado, 1996, p. 163.

${ }^{28}$ PIOVESAN, Flávia. Op. cit., p.144.

REDESG / Revista Direitos Emergentes na Sociedade Global - www.ufsm.br/redesg v. 1, n. 1, jan.jun/2012
} 
O direito ao meio ambiente saudável pertence ao ramo da terceira geração de direitos, ou seja, é um direito coletivo por excelência, que busca através de uma solidariedade mundial obter o respeito à natureza por si mesma, e para o próprio homem. Já os direitos sociais, pertencem à segunda geração de direitos, também próprios de coletividade, que buscam a efetividade e igualdade dos direitos inerentes ao homem e sua qualidade de vida, saúde, moradia, assistência entre outros.

A efetivação dos direitos sociais, aqui interpretados como uma espécie dos direitos humanos dependerá da existência de um meio ambiente saudável, caso contrário, os direitos à saúde, qualidade de vida, moradia, trabalho entre outros ficariam comprometidos. Neste mesmo sentido, para que haja preservação ambiental e uma conscientização da sociedade para com a mesma, é necessário que os direitos do homem, enquanto coletividade, sejam respeitados.

Pensar o direito ambiental em sua individualidade não cabe mais no mundo atual em que vivemos. A tecnologia e a globalização aproximam as diversas nações e demonstram com uma precisão cada vez maior que o meio ambiente é uno, indivisível pertencente a toda comunidade global.

Hoje já se evidencia conforme expõe o Relatório de Desenvolvimento Humano de 2007/2008, redigido pelo PNUD (Programa das Nações Unidas para o Desenvolvimento) que:

\begin{abstract}
A interdependência ecológica não é um conceito abstracto. Actualmente vivemos num mundo dividido, a vários níveis. Os povos estão afastados por profundos hiatos de riqueza e oportunidades. Em muitas regiões, nacionalismos rivais são fonte de conflito. Demasiadas vezes, as identidades religiosas, culturais e étnicas são tratadas como fonte de cisões e diferenças para com o outro. Face a todas estas distinções, as alterações climáticas recordam-nos vivamente aquilo que todos nós temos em comum: chama-se planeta Terra. Todas as nações e todos os povos partilham a mesma atmosfera. E temos apenas uma. ${ }^{29}$
\end{abstract}

Esta conscientização de que se partilha de um só mundo, é pensamento moderno, que se introduz diante das nações em virtude dos efeitos que a degradação contínua e progressiva do meio ambiente, vem causando perante as populações do

\footnotetext{
29 WATKINS, K. Relatório de Desenvolvimento Humano 2007/2008: combater as alterações climáticas, solidariedade humana num mundo dividido. New York: PNUD 2007, tradução de CEQO, p. 02.

REDESG / Revista Direitos Emergentes na Sociedade Global - www.ufsm.br/redesg v. 1, n. 1, jan.jun/2012
} 
mundo inteiro, os reflexos dessa degradação ambiental atingem diretamente a sociedade e consequentemente os seus direitos.

Assim como os problemas ambientais possuem características unas, de amplitude mundial, também se tornam indivisíveis deste problema os direitos do homem em sociedade, afinal quando se percebeu a necessidade da interdependência entre as gerações de direitos, e os direitos sociais e ambientais se tornaram direitos fundamentais aos seres humanos, se estabeleceu a interdependência e indivisibilidade dos direitos humanos para com a proteção ambiental e social.

Edson Ferreira de Carvalho, afirma em sua obra que:

0 princípio $1^{\circ}$ da Proposta de Declaração de Princípios sobre Direitos Humanos e Meio Ambiente reafirma essa visão holística complexa de que direitos humanos, o ambiente ecologicamente saudável, o desenvolvimento sustentável e a paz são interdependentes e indivisíveis. Ao se fazer a relação entre direitos humanos e meio ambiente, torna-se indiscutível a notória relevância que este exerce no desfrute daqueles. ${ }^{30}$

Os direitos humanos devem estabelecer a proteção ambiental como um direito fundamental ao ser humano, que dele é indivisível e dependente, visto que o ferimento ou a degradação do meio ambiente implicam diretamente ao direito à vida do homem.

Para se ter uma vida digna, saudável, é imperioso que o habitat, o local onde se expande a vida humana seja ecologicamente equilibrado, e tenha condições mínimas para sua sobrevivência, ou seja, precisa-se da presença dos direitos ambientais e sociais.

Conforme a sociedade evolui, suas necessidades se transformam, e novos direitos vão surgindo, aquilo que antes não parecia necessário para concretizar uma vida humana digna, hoje torna-se requisito essencial para a mesma.

A proteção ao meio ambiente nesses termos será considerada como um meio para se conseguir o cumprimento dos direitos humanos e sociais, pois na medida em que ocorre um dano ao ambiente, consequentemente, haverá infração à outros direitos fundamentais do homem, como a vida, a saúde, o bem estar; direitos estes, reconhecidos internacionalmente.

${ }^{30}$ CARVALHO, E.F. Meio ambiente como patrimônio da humanidade: princípios fundamentais. Curitiba: Juruá, 2009, p. 48.

REDESG / Revista Direitos Emergentes na Sociedade Global - www.ufsm.br/redesg v. 1, n. 1, jan.jun/2012 
Há autores como Edson Carvalho, que afirmam que a relação entre a proteção ambiental e direitos humanos é tão intrínseca que a inexistência de um ambiente ecologicamente equilibrado implica inexistência do homem e por consequência, a dos direitos humanos. ${ }^{31}$

Deve se observar que não se pretende instituir um pensamento antropocêntrico exclusivo, de que o homem seja o centro do universo e da proteção ambiental, muito pelo contrário à visão de interdependência não concebe a individualidade em particular, mas sim almeja estabelecer um biocentrismo, ou seja, que concilie as duas esferas meio ambiente em si mesmo e seres humanos, complementado-as e não as excluindo.

A Carta Mundial da Natureza, proferida em 1982, afirmava que "a espécie humana é parte da natureza e a vida depende do funcionamento ininterrupto dos sistemas naturais que são fonte de energia e de matérias nutritivas; a civilização tem suas raízes na natureza [...]". ${ }^{32}$

O homem faz parte do meio ambiente, e dele adveio, não há como considerá-los distintos se um depende do outro para existir. O homem só existe porque a natureza lhe fornece os recursos necessários a sua sobrevivência, tais como os alimentos, a água, o ar, o clima, o solo, e assim por diante. Sem estes recursos não existe e não se constitui vida.

Se o direito à vida é um direito humano universal e fundamental o direito a proteção ambiental também o é. O direito humano e o direito a um ambiente sadio estão interligados, pois ambos buscam preservar à vida, ou melhor, a qualidade de vida na Terra, e quando se busca a qualidade de vida e saúde do homem, busca-se a efetividade dos seus direitos sociais. São direitos que, onde houver a violação de um, haverá do outro, posto que, se violados, invadem um o campo do outro, constituindo um duplo desequilíbrio, tanto ambiental quanto humano.

Antônio Cançado Trindade dispõe em sua obra à relação que o direito à vida e ao meio ambiente sadio possuem com o direito ambiental:

\footnotetext{
${ }^{31}$ CARVALHO, E.F. Op. cit., p. 48.

32 UNIVERSAL. Carta Mundial da Natureza, de 09 de novembro 1982, UNGA Resolução 37/7. Este documento pode ser encontrado em: CARVALHO, E.F. Op. cit., p.180, Anexo II.

REDESG / Revista Direitos Emergentes na Sociedade Global - www.ufsm.br/redesg v. 1, n. 1, jan.jun/2012
} 
A dimensão ampla do direito à vida e o direito a um meio ambiente sadio acarretam a consequente caracterização mais ampla de atentados ou ameaças a estes direitos, o que em contrapartida requer um maior grau de sua proteção. Um exemplo de tais ameaças é fornecido pelos efeitos do aquecimento global sobre a saúde humana: câncer de pele, lesão na retina ocular, [...] menor resistência a infecções, em suma a destruição a camada de ozônio pode resultar em danos substanciais a saúde humana assim como ao meio ambiente [...]. ${ }^{33}$

Desse modo, o direito fundamental à vida, abrangendo o direito de viver e o direito às condições para essa sobrevivência, impõe condições negativas e positivas em favor da preservação da vida humana.

José Afonso Silva menciona em sua obra que:

O problema da tutela jurídica do meio ambiente manifesta-se a partir do momento em que sua degradação passa a ameaçar não só o bem-estar, mas a qualidade da vida humana, se não a própria sobrevivência do ser humano [...] 0 que é importante é que se tenha consciência de que o direito à vida, como matriz de todos os direitos fundamentais do homem, é que há de orientar todas as formas de atuação no campo de tutela do meio ambiente. Cumpre compreender que ele é um fator preponderante, que há de estar acima de quaisquer outras considerações como as de desenvolvimento, como as de respeito ao direito de propriedade e como as de iniciativa privada. ${ }^{34}$

O meio ambiente assim considerado, constitui a plataforma física que sustenta, nutre, permite e fundamenta a vida humana. É nesta concepção de proteção à natureza como proteção à vida humana que se sustenta tanto nacional quanto internacionalmente, a maior parte de considerações que ponderam sobre a indivisibilidade que existe entre as duas proteções.

Assim, pode-se estabelecer uma prévia relação entre todos estes conceitos fundamentais, para que se apresente de forma clara o conceito de indivisibilidade entre os direitos humanos na sua concepção geral, os direitos sociais e ambientais: para termos direito à vida precisamos do meio ambiente, para fazer dela digna é necessário que sejam oferecidos os meios básicos e necessários para o ser humano sobreviver, como por exemplo, um meio ambiente sadio; um meio ambiente ecologicamente equilibrado

\footnotetext{
${ }^{33}$ TRINDADE, A.A.C. Direitos humanos e meio-ambiente: paralelo dos sistemas de proteção internacional. Porto Alegre: Sérgio Antônio Fabris, 1993, p. 76.

${ }^{34}$ SILVA, J.A. Direito ambiental constitucional. São Paulo: Malheiros, 2000, p.28/67.

REDESG / Revista Direitos Emergentes na Sociedade Global - www.ufsm.br/redesg v. 1, n. 1, jan.jun/2012
} 
implica em uma boa qualidade de vida, e consequentemente uma boa saúde, a preservação da natureza para garantir os direitos fundamentais aos seres humanos hoje, acarretará a preservação para as gerações de amanhã.

De primeiro momento esta relação pode parecer complexa e confusa, mas se analisarmos de forma sucinta o que ela quer expressar é que sucessivamente os direitos vão se interligando e apresentando cada vez mais características de universalidade, indivisibilidade e interdependência. Todos existem e são válidos, mas para se tornarem eficazes, devem ser interpretados em um conjunto único.

Estabelecer esta importância da indivisibilidade entre os direitos à sociedade humana e o meio ambiente, não significa colocar essa proteção acima de qualquer outra, as gerações que surgem ou os "novos direitos” não sobrepõem as antigas, mas sim as complementam, sendo todas essas esferas fundamentais ao equilíbrio ecológico do planeta.

Uma forma de visualizar a relação indivisível que existe entre o homem e o meio ambiente atualmente, se concretiza nas palavras de Peter Singer em uma de suas várias descrições dos problemas ambientais no sentido de que, por exemplo, “[...] devido ao aquecimento dos oceanos, os ciclones e as tempestades tropicais, antes confinadas aos trópicos, afastar-se-ão do Equador, atingindo áreas urbanas que não foram construídas para suportá-los". 35

Dessa forma, todos os problemas ambientais acabam por refletir diretamente sobre os seres humanos, e é por isso que entre eles não pode existir dissociação.

Antigamente era aceitável o argumento que em virtude do progresso permitir-seia o uso indiscriminado dos recursos naturais, a sociedade não tinha consciência nem meios de saber a dimensão que aquela exploração the acarretaria no futuro. Diga-se que o grande erro das civilizações anteriores, é de certa forma perdoável uma vez que não se tendo consciência dos erros, não há como mensurá-los.

Contudo, atualmente já não cabe mais esta posição. A tecnologia avançada, e o processo de globalização e internacionalização permitem que cada ser humano tenha

\footnotetext{
${ }^{35}$ SINGER, P. Um só mundo: a ética da globalização. São Paulo: Martins Fontes, 2004, p. 23.

REDESG / Revista Direitos Emergentes na Sociedade Global - www.ufsm.br/redesg v. 1, n. 1, jan.jun/2012
} 
total consciência e dimensão dos estragos que causarão as presentes e futuras gerações caso continuem a usufruir irrestritamente dos recursos naturais.

Estando a sociedade ciente de tais riscos, é necessário que haja uma mudança de atitude da civilização e de seus hábitos para com o meio ambiente. A crise ambiental implica em uma crise da civilização atual, onde os valores éticos e morais devem ser revistos para que o homem possa se inserir como ser da natureza, que analise o meio ambiente nos aspectos relacionados à sua biodiversidade, às alterações introduzidas pelo ser humano e os efeitos dessas ações, bem como os impactos sociais dessas atividades, fazendo ponderações entre interesses econômicos e ecológicos, sem anular um ou outro.

É nessa visão de ponderação e consideração do homem e meio ambiente como seres unos e indivisíveis, que se constitui o conceito de socioambientalismo, interpretado como a aplicação do princípio da indivisibilidade dos direitos humanos entre os direitos sociais e à proteção ambiental.

0 conceito socioambiental se estabelece no momento em que se percebe que a proteção ambiental está intimamente relacionada com a proteção humana, e que sua extensão é global, universal. Ou seja, o meio ambiente de determinada sociedade não é só aquele que a rodeia, é tudo que contribui para sua subsistência e desenvolvimento, independentemente de tempo e lugar.

Aderir à compreensão do socioambientalismo é pensar que a proteção ambiental e a proteção a sociedade humana devem ser consideradas em conjunto, ou seja, para chegar a um patamar de conservação ambiental que seja efetiva, deve-se considerar a sociedade que a envolve, observando todas suas necessidades. Se forem instituídas leis ambientais muito rígidas que não visem e não incluam a sociedade e seus direitos, podese acabar ferindo ou até mesmo anulando direitos sociais que são fundamentais. Bem como, se forem considerados os direitos sociais como superiores ou dependentes do direito ambiental, o homem estará sendo afastado do meio em que se constituiu, e, por conseguinte, contribuindo para o aumento da destruição ambiental.

O socioambientalismo busca diminuir as disparidades sociais que decorrem do meio ambiente, a falta de alimentos, água, saneamento, moradia, trabalho, saúde, todas essas questões sociais que decorrem de alguma maneira da degradação ambiental, 
mas também traz como necessária a conscientização da sociedade de que para que os direitos sociais se efetivem, é imprescindível que o meio ambiente global seja protegido e preservado.

Como já se afirmou diversas vezes, o homem é uma das partes do complexo ambiental, portanto não há como tentar resolver seus problemas sociais se não considerar o meio ambiente em que vive, porque dele dependerá a sua própria existência.

A indivisibilidade dos direitos humanos concretiza então o conceito socioambiental como a relação entre os direitos sociais e à proteção ambiental, de maneira que o grande desafio atual, diante da crise ambiental e social que se vivencia é propiciar condições dignas de vida às populações carentes dando-lhes acesso aos direitos sociais, respeitando-se o direito-dever ao meio ambiente ecologicamente equilibrado, visando o bem estar da humanidade em caráter universal.

\section{CONCLUSÃO}

O modelo de sociedade que se introduziu das gerações antigas trouxe consigo e para as posteriores gerações uma cultura consumista e egoísta, onde os interesses individuais se sobrepunham aos coletivos, e a ganância por progresso financeiro passou a ser justificativa pra toda e qualquer degradação ambiental. O homem não se concebia como parte do meio ambiente, e por isso sempre o utilizou como um meio, um recurso inesgotável.

Ainda hoje, mesmo com toda evolução da sociedade e das tecnologias que permitem mensurar as consequências que a utilização de determinado recurso natural ensejará ao meio ambiente e a sociedade que o envolve, é possível vislumbrar em muitos aspectos o descaso da coletividade para com estes resultados. Pode-se dizer que a sociedade hoje caminha rumo à conscientização e inserção ao meio ambiente natural, mas ainda não se desvencilhou da sua cultura e carga individualista advinda das gerações passadas.

0 conceito da indivisibilidade dos direitos humanos ligado à questão ambiental, discorrido durante a pesquisa, é antigo e já solidificado na doutrina, entretanto, ainda encontra obstáculos quando se posta de frente ao crescimento industrial, tecnológico, rural, populacional, etc. Para tentar diminuir ou amenizar esse conflito de interesses, a fim de que não haja opções REDESG / Revista Direitos Emergentes na Sociedade Global - www.ufsm.br/redesg v. 1, n. 1, jan.jun/2012 
por um ou outro, mas sim por um pouco de ambos em equilíbrio, é que se vislumbra emergente a introdução do conceito socioambiental perante a sociedade global. Proteger $0 \quad$ meio ambiente por si mesmo, e para preservar e fornecer a sociedade que o envolve melhores condições de vida, saúde, moradia, etc. é medida que se impõe.

Para que homem se insira definitivamente no meio ambiente e passe a considerá-lo como parte de si mesmo é preciso importar dos direitos humanos a compreensão da indivisibilidade, e aplicá-la como princípio base e estruturador da relação sociedade e meio ambiente.

Assim, se corrobora que para que haja efetividade de direitos sociais e ambientais é imprescindível uma interpretação baseada no princípio da indivisibilidade entre ambos, que considere o homem e meio ambiente como conceito único, em equilíbrio, onde a existência de um dependerá do outro. Desta maneira será possível confirmar que o conceito socioambiental, que advém desta relação, é, diante das grandes desigualdades sociais que se presencia atualmente, o melhor conceito para instituir uma preservação ambiental que vise além do meio ambiente, proteger também a sociedade que nele habita.

\section{REFERÊNCIAS}

ADM, Aula. Complexo ambiental: conceitos e evolução histórica. Disponível em: <http://www.aulaadm.pro.br/GEST\%C3\%830_SOCIOAMBIENTAL.CAP\%C3\%8DTULO2.pdf>. Acesso em: 14 jul. 2012.

BOBBIO, N. A era dos direitos. Rio de Janeiro: Campus, 1997.

BOFF, L. Ética e moral: a busca dos fundamentos. Petrópolis, RJ: Vozes, 2003.

BONAVIDES, P. Curso de direito constitucional. 7. ed. São Paulo: Malheiros, 1998.

CARVALHO, E.F. Meio ambiente como patrimônio da humanidade: princípios fundamentais. Curitiba: Juruá, 2009.

CHACON, S.S. Reflexões sobre a crise ambiental: uma viagem até suas origens. Disponível em: $<$ http: / / www.cofecon.org.br/index.php?option=com_content\&task=view\&id=796\&ltemid=51 >. Acesso em: 16 jul. 2012.

COIMBRA, J.A.A. O outro lado do meio ambiente: uma incursão humanista na questão ambiental. Campinas, SP: Millennium, 2002. 
COMISSÃO MUNDIAL SOBRE MEIO AMBIENTE E DESENVOLVIMENTO. Nosso futuro comum. Rio de Janeiro: Fundação Getúlio Vargas, 1988.

DORST, J. Antes que a natureza morra: por uma ecologia política. 6. ed. São Paulo: Edgar Blucher, 1973.

GONÇALVES, C.W.P. Os (Des)caminhos do meio ambiente. São Paulo: Contexto, 2006.

LEFF, E. Saber ambiental: sustentabilidade, racionalidade, complexidade, poder. Petrópolis, RJ: Vozes, 2001.

MORAIS, J.L.B. Do direito social aos interesses transindividuais: o estado e o direito na ordem contemporânea. Porto Alegre: Livraria do Advogado, 1996.

OLIVEIRA, R.S. Direito ambiental internacional: o papel da soft law em sua efetivação. ljuí, RS: Unijuí, 2007.

PIOVESAN, F. Direitos humanos e o direito constitucional internacional. 10. ed. São Paulo: Saraiva, 2009.

SANTILLI, J. Socioambientalismo e novos direitos: proteção jurídica a diversidade biológica e cultural. São Paulo: IIEB, 2005.

SILVA, J.A. Direito ambiental constitucional. São Paulo: Malheiros, 2000.

SILVA, José Afonso da. Direito Ambiental constitucional. São Paulo: Malheiros, 2002.

SINGER, P. Um só mundo: a ética da globalização. São Paulo: Martins Fontes, 2004.

SIRVINSKAS, L.P. Manual de direito ambiental. 7. ed. São Paulo: Saraiva, 2009.

SOUZA FILHO, Carlos Frederico Marés de. Introdução ao direito socioambiental. In: LIMA, André (Org.) O direito para o Brasil socioambiental. Porto Alegre: Fabris, 2002.

TRINDADE, A.A.C. A proteção internacional dos direitos humanos. São Paulo: Saraiva, 1992.

TRINDADE, A.A.C. Direitos humanos e meio-ambiente: paralelo dos sistemas de proteção internacional. Porto Alegre: Sérgio Antônio Fabris, 1993.

UNIVERSAL. Carta Mundial da Natureza, de 09 de novembro 1982, UNGA Resolução 37/7. Este documento pode ser encontrado em: CARVALHO, E.F. Op. cit., p.180, Anexo II.

UNIVERSAL. Declaração de Estocolmo sobre Meio Ambiente Humano, de 16 de junho de 1972. Conferência das Nações Unidas. Disponível em:<http://www.dhnet.org.br/direitos/sip/onu/doc/estoc72.htm>. Acesso em: 13 jun. 2012. 
ISSN 2316-3054

UNIVERSAL. Declaração Universal dos Direitos Humanos, de 10 de dezembro de 1948. Assembleia Geral das Nações Unidas, Resolução 217(A) III. Disponível em:

<http://www.mj.gov.br/sedh/ct/legis_intern/ddh_bib_inter_universal.htm>. Acesso em: 12 out. 2011.

WATKINS, K. Relatório de Desenvolvimento Humano 2007/2008: combater as alterações climáticas, solidariedade humana num mundo dividido. New York: PNUD 2007, tradução de CEQO.

WIKIPÉDIA. A enciclopédia livre. Disponível em: <http://pt.wikipedia.org/wiki/Sociedade>. Acesso em: 2 jun. 2012.

Recebido em: 30.07.2012 / Aprovado em: 20.09.2012 